\title{
THE EFFECTS ON THE COMPOSITION OF THE BLOOD OF THE SUBCUTANEOUS INJECTION OF NORMAL SALT SOLUTION INTO NORMAL DOGS AND INTO DOGS SUBJECTED TO INTESTINAL TRAUMA, GRADED HEMORRHAGES AND HISTAMINE INJECTION
}

\author{
By ALFRED BLALOCK AND J. W. BEARD \\ (From the Department of Surgery, Vanderbilt University, Nashville)
}

(Received for publication September 3, 1931)

In previous studies $(1,2,3)$, the effects on the composition of the blood of the introduction of fluids intravenously have been determined on normal animals and on animals in which a decline in blood pressure had been produced by a variety of means. Another method frequently employed by which fluids may be introduced consists of injection into the subcutaneous tissues. For this purpose, normal salt solution is used most often. The present studies were undertaken in order to determine the effects on the composition of the blood of the subcutaneous injection of normal salt solution into normal dogs and into dogs in which a decline in blood pressure was produced by several different methods. Also we were interested in determining how much of the fluid that was placed in the tissues was absorbed into the general circulation. For this reason all of the fluid was injected into the tissues of one posterior extremity, groin and flank. At the completion of the experiments, the difference in the weights of the two posterior portions of the body was determined.

\section{METHODS}

Dogs were used in all experiments. Morphine sulphate was employed as an anesthetic in all experiments except those in which the intestines were traumatized. Sodium barbital was used in these. The animals gave no evidence of pain during the course of the experiments. The blood pressure was determined by placing a cannula that was connected to a mercury manometer into the carotid artery. Specimens of blood for the various analyses were obtained from the femoral vein of the extremity into which no fluid was injected and this blood was replaced by an equal amount obtained from a normal dog.

Four different types of experiments were performed. In all of these, following the replacement of the blood which was removed in order to determine the blood volume, hemoglobin, hematocrit, total protein, albumin and globulin, normal salt solution was injected continuously into the tissues of one of the posterior extremities, groin and flank. It was given at body temperature at the rate of $10 \mathrm{cc}$. per kilogram of body weight per hour for four hours. Samples of blood for the various analyses were obtained one and two and one-half hours 
following the beginning of the injection and at its completion. Further samples were obtained after intervals of one and one-half and three hours. The animals were then killed and the difference in the weights of the two posterior portions of the body was determined. In the first group of experiments, the effects on the composition of the blood of the introduction of fluids into the subcutaneous tissues of normal animals were studied. In the second group, after making a midline abdominal incision, the intestines were traumatized during the four hours while fluid was being injected by gently passing them between the fingers. At the end of this time, the incision was closed, and two further series of determinations were performed during the following three hours. In the third group of experiments, the effects of graded hemorrhages at the same time that fluid was being introduced subcutaneously were studied. As in all experiments normal salt solution was injected at the rate of $10 \mathrm{cc}$. per kilogram of body weight per hour for four hours and samples of blood were obtained at the usual times. After performing the control determinations, whole blood which equalled one per cent of the body weight was removed from the femoral artery. Blood equalling approximately one and one-half per cent of the body weight was withdrawn one hour later and two and one-half hours later. The volume of the blood that was removed was slightly less than the volume of salt solution that was introduced. The observations were continued for three hours after the completion of the injection of salt solution. In the fourth group of experiments, histamine was injected intermittently into the subcutaneous tissues during the four hours that salt solution was being introduced. It was given in amounts sufficiently large to produce a definite decline in the blood pressure. The usual determinations were performed during the three hours following the termination of the injections.

Van Allen tubes were used in the hematocrit determinations. Hemoglobin. estimations were performed by the method of Cohen and Smith (4). The control blood volume was determined by the dye method as employed by Rowntree, Brown and Roth (5). These figures are placed in brackets in the tables. During the course of the experiments, excepting those on hemorrhage, the alterations in the total blood volume were assumed to vary in an inverse ratio to the changes in the percentage of hemoglobin. The volumes of red blood cells and of plasma were calculated from the hematocrit readings. In the experiments in which graded hemorrhages were performed, the calculations were different in that after determining the volume by the method described above, subtraction was made for the amount removed. The determinations of the nitrogen were performed on blood serum. Albumin and globulin were separated by the use of 22.2 per cent sodium sulphate as recommended by Howe (6). The Gunning (7) modification of the Kjeldahl method was employed for determining the albumin and total protein nitrogen of the serum. The total nitrogen of the urine was also determined by this method. In all the tables the nitrogen is expressed as protein. The figures for the entire or absolute amounts of protein were obtained by multiplying the percentage of protein per unit volume of serum by the total amount of plasma in the blood stream. In the experiments on hemorrhage, the figures in brackets represent the addition of the total protein, albumin and globulin that were removed at the time of the bleedings to the calculated absolute amounts of each that remained in the blood stream. Analyses were performed on the blood that was injected in order to replace that removed for the various determinations. The differences between the blood removed and that injected were ignored in the calculations. This introduced very little error. 
The method (8) by which the posterior part of the body was divided into two parts was as follows. An abdominal incision was made in the midline line. The symphysis pubis was divided with a saw. The bladder and rectum were removed. The abdominal aorta and vena cava were doubly ligated and divided. The iliac vessels were clamped. A transverse abdominal incision was made at approximately the level of the umbilicus. This was extended through the vertebral column and the front part of the body was discarded. Using a knife and a saw, the structures on either side of the vertebral column of the posterior part were divided in a longitudinal direction. This resulted in a separation of the spinal column and tail from the two posterior portions of the body. The difference in the weight of the part into which fluid had been injected and the opposite part was determined.

\section{RESULTS}

\section{The effects of the subcutaneous injection of normal salt solution}

Three experiments were performed in which the effects on the composition of the blood of the subcutaneous injection of normal salt solution were determined. The blood pressure remained at approximately the control level in all of the experiments. There was usually a slight diminution in the concentration of red blood cells, and in the percentage of hemoglobin. There was a slight but definite increase in the volume of plasma in all experiments. The alterations in the percentages of total protein, albumin and globulin in the blood serum were very minor. There was an increase in the absolute amounts of total protein, albumin and globulin in the blood plasma in all experiments. Determinations of the difference in the weights of the two posterior extremities in the three experiments indicated that 29 per cent of the fluid that was injected was absorbed into the general circulation. The results of these experiments are given in Table I.

\section{The effects of continuous trauma to the intestines and of the subcutaneous injection of normal salt solution}

Continuous trauma to the intestines and the subcutaneous injection of normal salt solution were associated with varying degrees of decline in the blood pressure. There was an increase in the concentration of the red blood cells and an increase in the percentage of hemoglobin. The volume of blood plasma decreased in all experiments. The percentages of total protein, albumin and globulin in the blood serum remained at approximately the control levels throughout the experiments. There were rather marked decreases in the absolute amounts of the protein constituents in all experiments. Comparison of the weights of the posterior extremities indicated that 17 per cent of the fluid that was injected in the three experiments was absorbed. The results of these experiments are enumerated in Table II. 


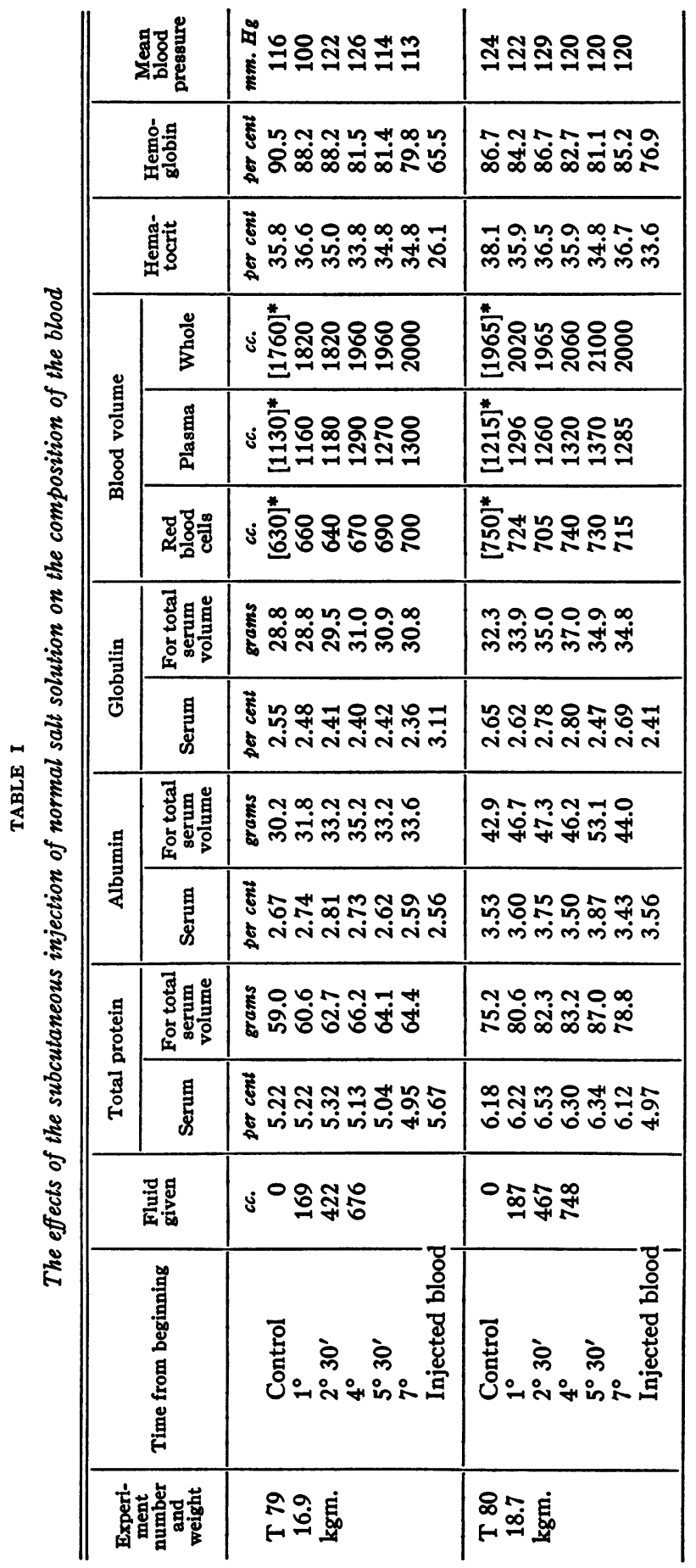




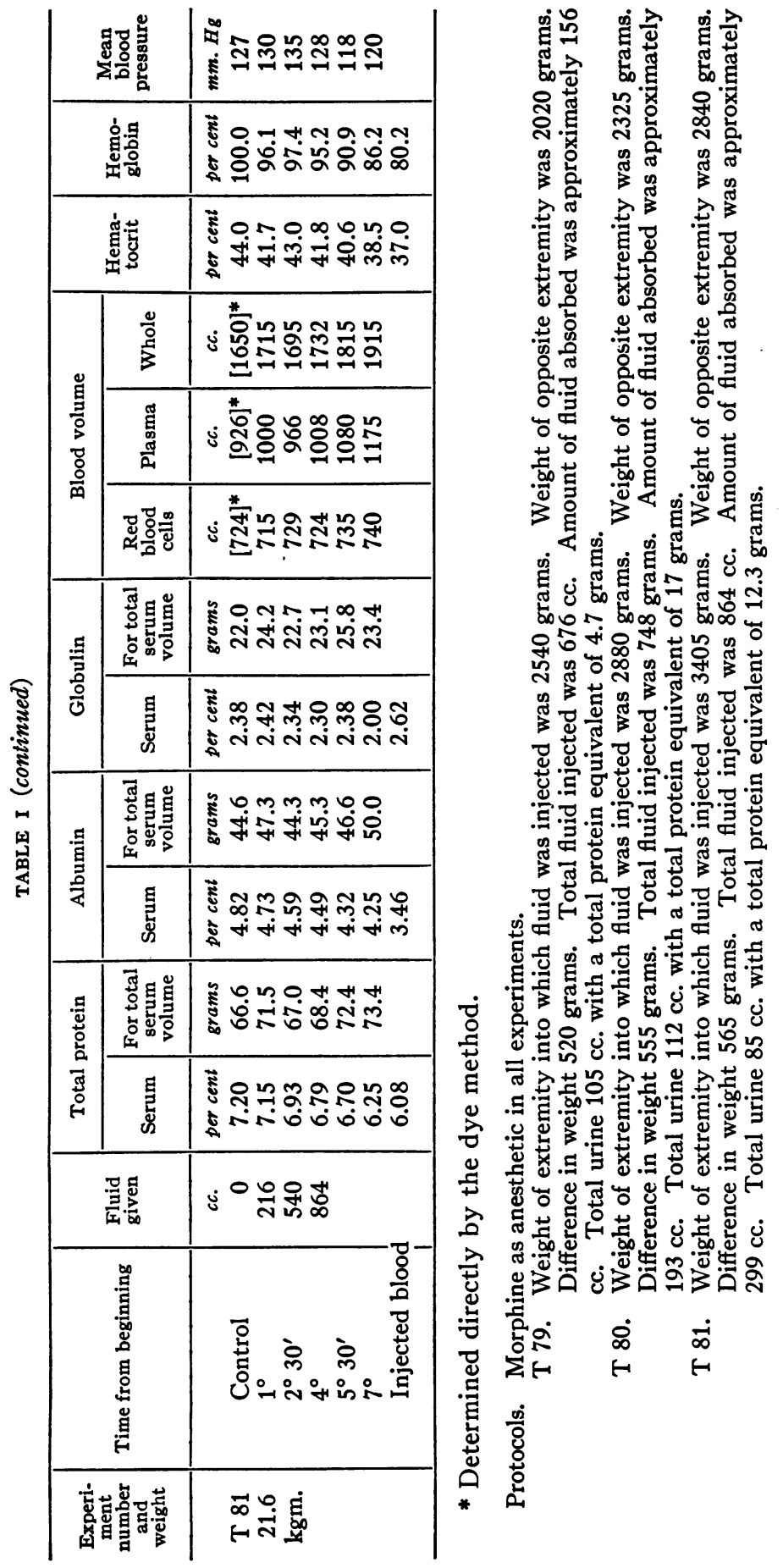




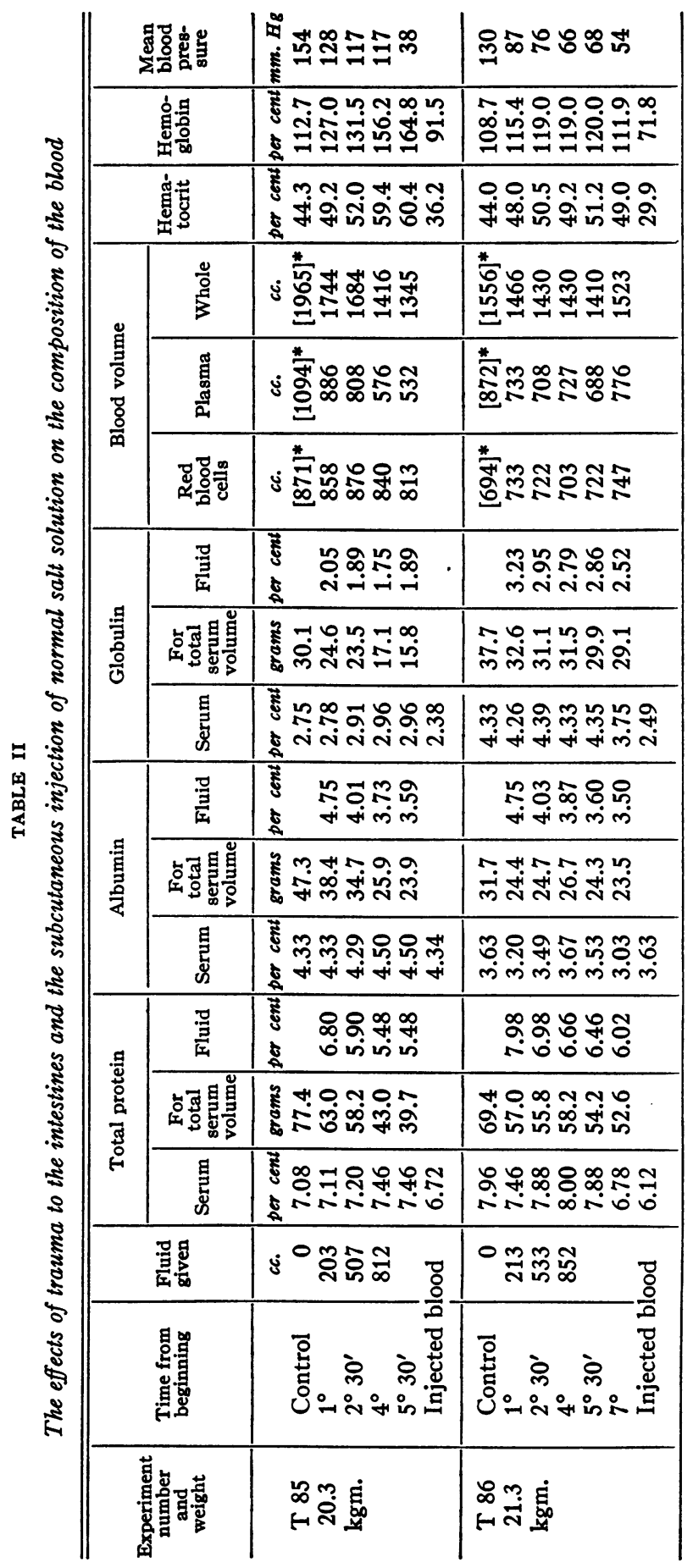




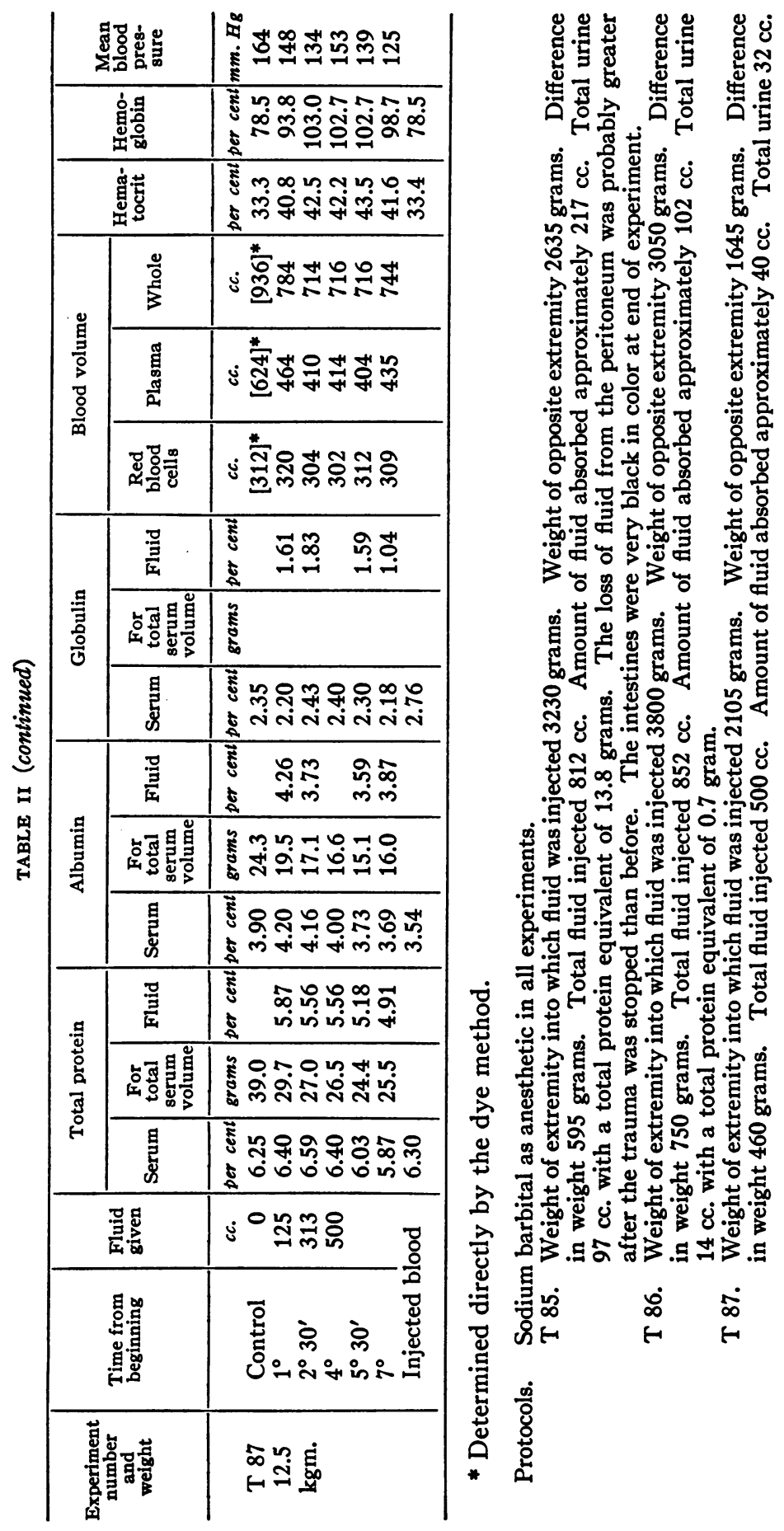




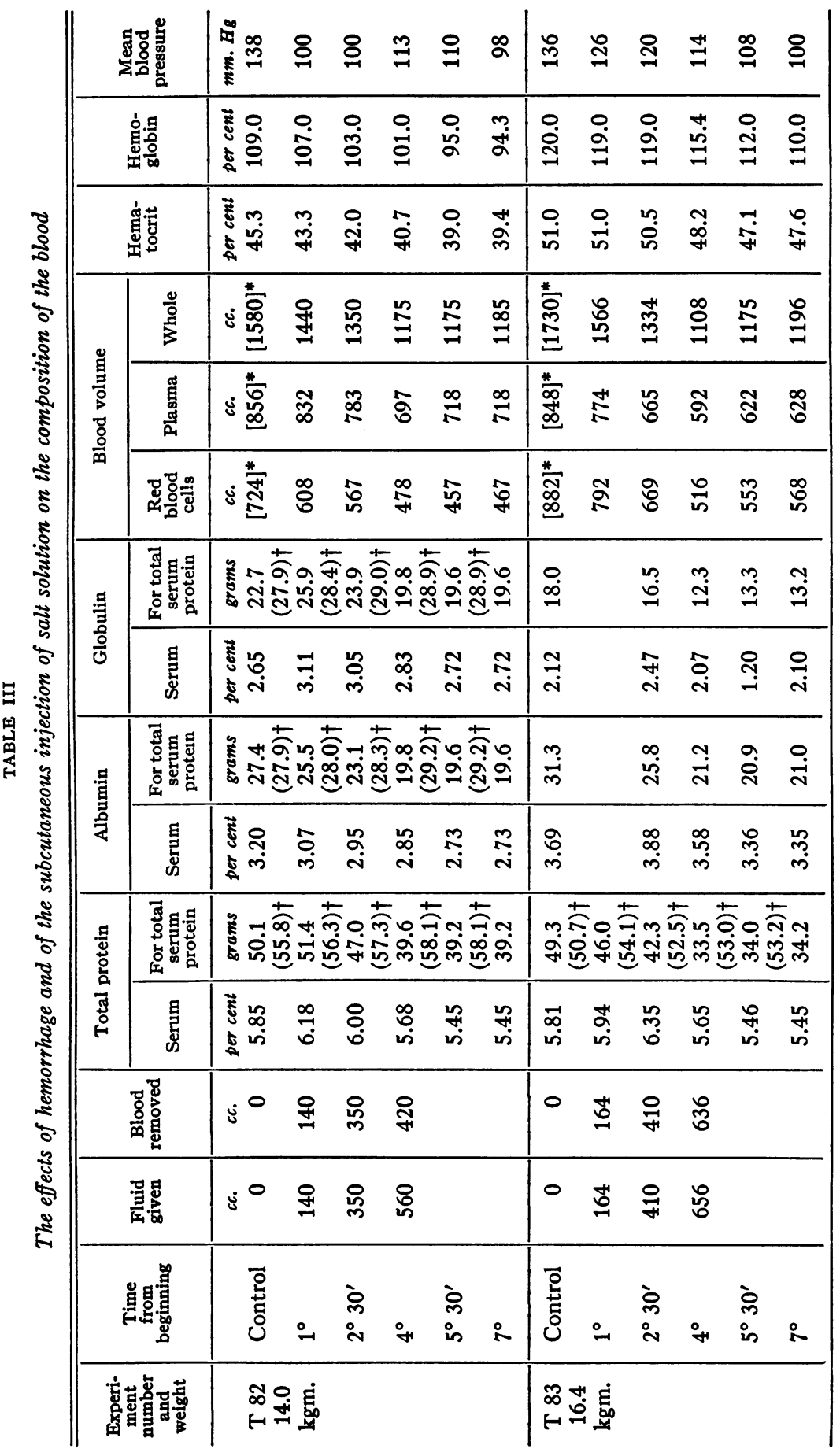




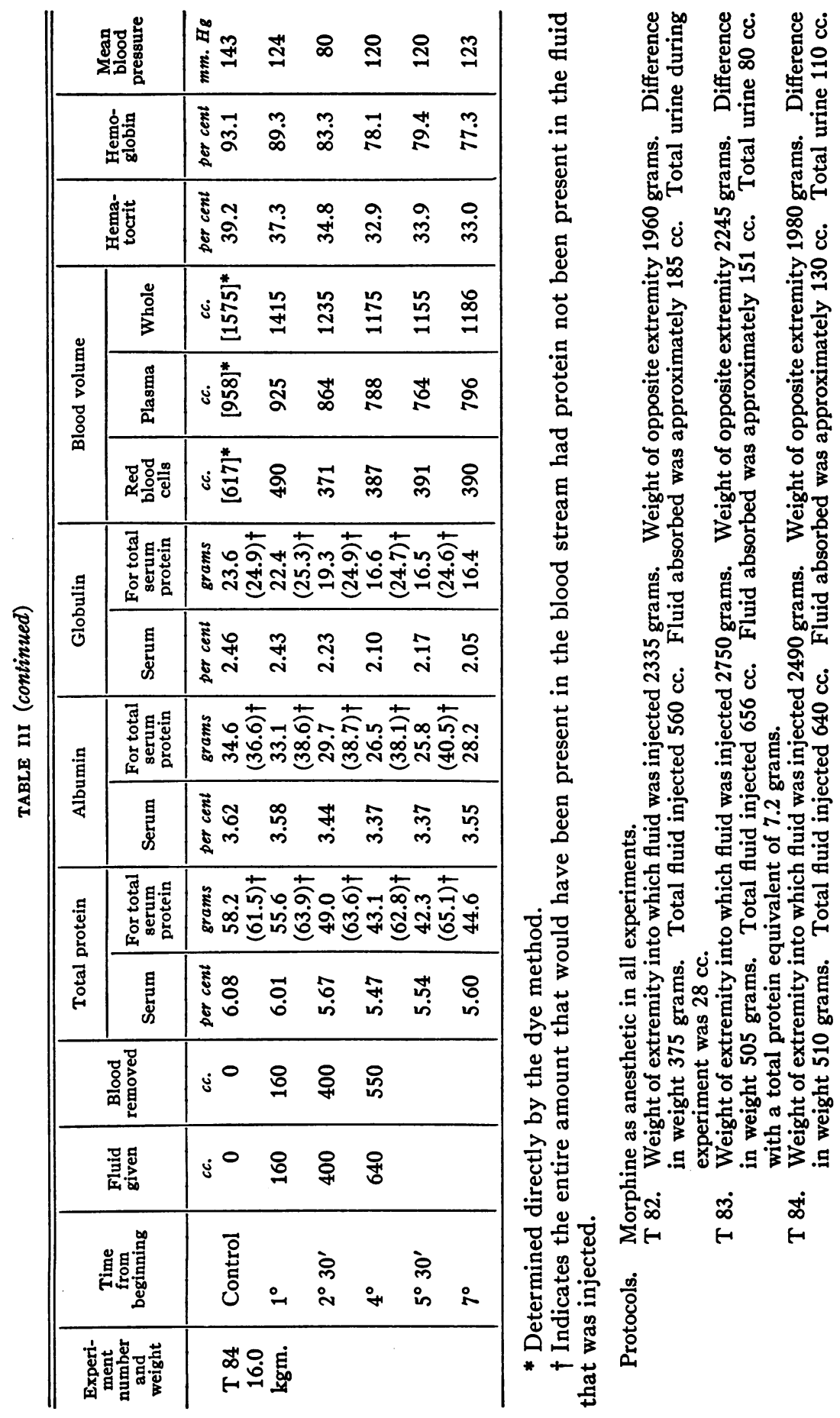




\section{The effects of graded hemorrhages and of the subcutaneous injection of normal salt solution}

In the three experiments in which the effects of graded hemorrhages and the subcutaneous injection of salt solution were studied, the removal of blood was sufficient to cause a definite decline in the blood pressure. There was a decrease in the hematocrit readings and in the percentage of hemoglobin in all experiments. The volumes of whole blood, plasma, and red blood cells decreased when the amount of blood that was removed is taken into consideration. There was a slight decrease in the percentages of total protein, albumin and globulin in the blood serum. The absolute amounts of the protein constituents that remained in the blood plasma decreased. However, if one adds to that remaining in the blood stream the amount corresponding to the protein removed by bleeding, it is to be noted that protein probably passed into the vessels during the course of the experiments. These figures are placed in brackets in the tables. Approximately 25 per cent of the fluid that was injected into the extremities was absorbed. The results of these experiments are given in Table III.

\section{The effects of the subcutaneous injection of histamine and of normal salt solution}

A marked decline in the blood pressure was produced in the three experiments in which the effects of the subcutaneous injection of histamine and salt solution were studied. The blood pressure rose after the injections were terminated. There were marked increases in the concentration of the red blood cells and in the percentage of hemoglobin. There was a rather large diminution in the volume of plasma in the blood stream. The content of the blood serum in total protein, albumin and globulin altered very little. However, due to the loss of plasma, there was a great decrease in the absolute amounts of total protein, albumin and globulin. The difference in weight of the posterior extremities in the three experiments indicated that approximately 22 per cent of the fluid that was injected was absorbed. The results of these experiments are given in Table IV.

\section{DISCUSSION}

The significant alterations that accompanied the subcutaneous injection of salt solution into normal dogs consisted of a slight increase in the volume of plasma and in the absolute amount of plasma protein. The findings differ in the main from those previously reported (2) in which the fluid was given intravenously to normal dogs in that an appreciable decrease in the percentage of protein in the blood serum was not encountered in the present experiments. Less than one-third of the fluid that 


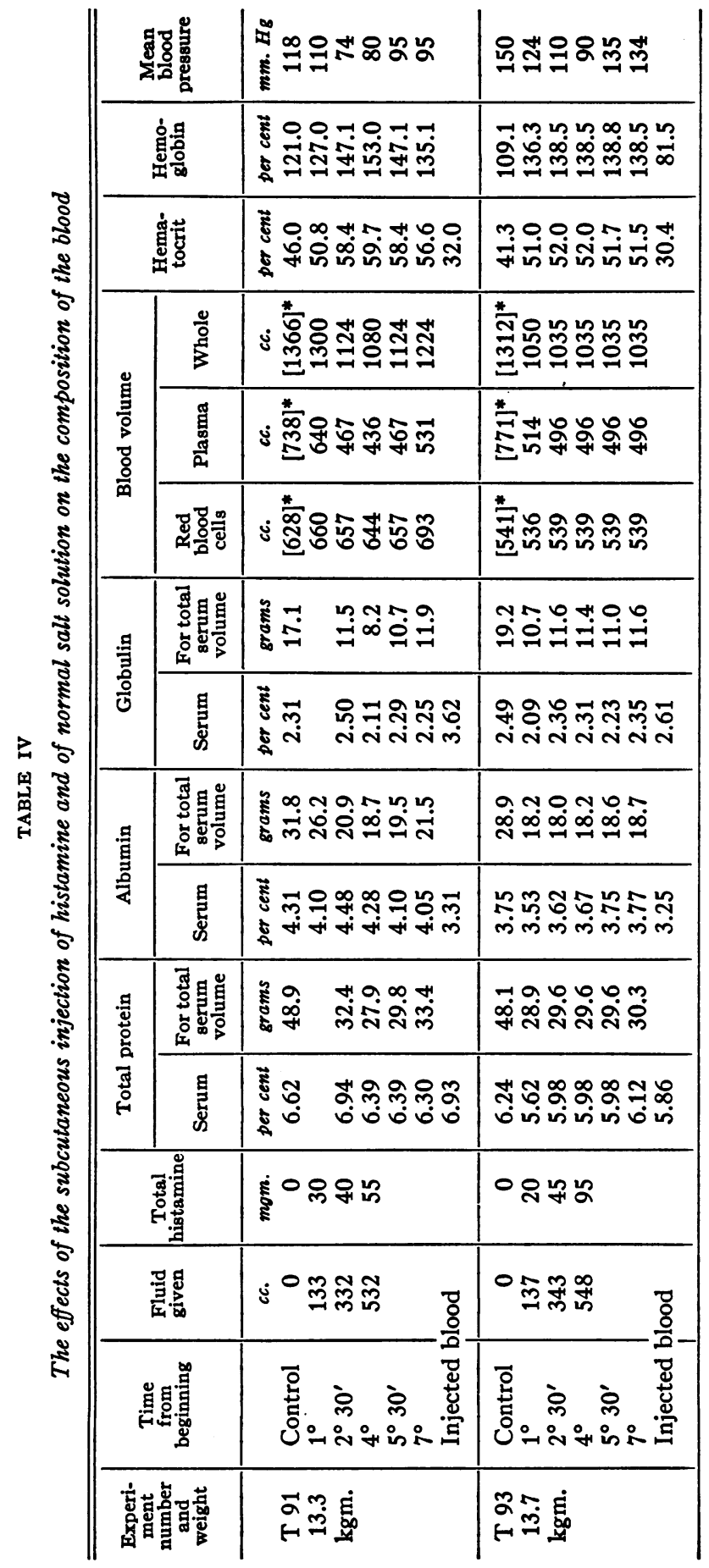




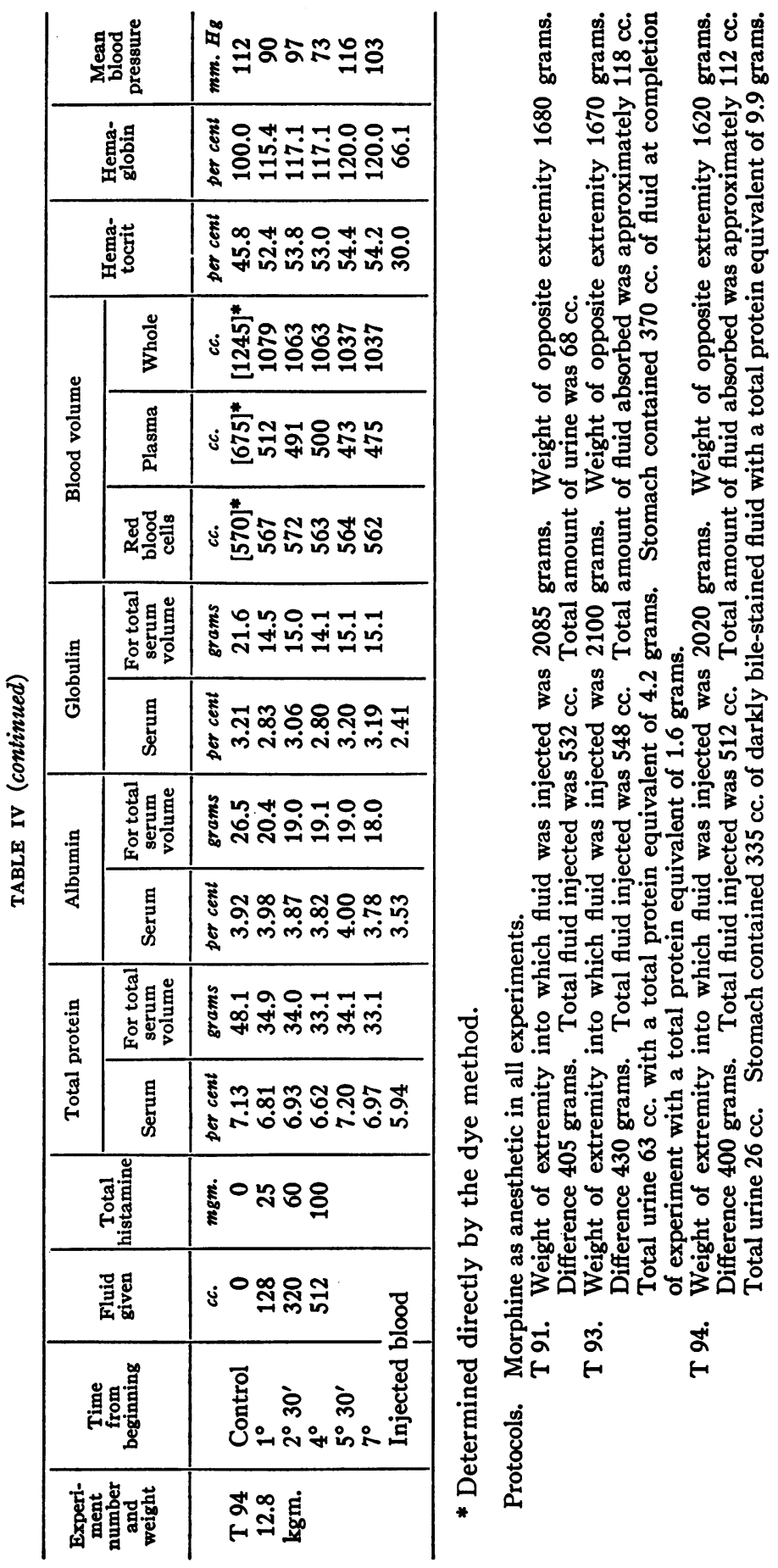


was injected was absorbed and the greater part of this could be accounted for by the urine that was passed.

The findings in the experiments in which the intestines were traumatized and those in which histamine was injected were quite similar. In each there was an increase in the concentration of the red blood cells, an increase in the percentage of hemoglobin, a decrease in the volume of plasma, very little alteration in the percentage of the protein constituents in the blood serum and a marked decrease in the absolute amounts of each. The proportion of the fluid that was absorbed was approximately the same in the two types of experiments. The percentage of fluid that was absorbed was less with these animals than with the normal ones. Similar experiments $(1,3)$ previously performed in which fluids were introduced intravenously instead of subcutaneously showed a decrease in the concentration of the protein constituents in the blood serum but otherwise essentially the same findings. It seemed to require more trauma to produce a given decline in the blood pressure when fluids were administered subcutaneously than was necessary in similar experiments in which no fluid was introduced.

In the studies on the effects of graded hemorrhages and the subcutaneous injection of normal salt solution, there was a decrease in the concentration of the red blood cells. The decrease was not quite as great as was usually found when the intravenous introduction of salt solution accompanied hemorrhage. The decrease in the plasma volume was not as great as the quantity of plasma removed. The decrease in the percentage of protein in the serum was less than was found when the fluid was given intravenously. If the protein that was removed with the blood is included, there was a definite increase in the absolute amount of plasma protein. This increase varied from five to eight grams in the different experiments.

The fact that the plasma protein increased in the experiments in which salt solution was injected subcutaneously in normal dogs and in dogs that were bled is of interest from a physiological viewpoint. The question arises as to whether the increase can be explained on the basis of osmosis alone or whether it is necessary to include backward filtration as accounting for part of it. This question we fear cannot be answered from our experiments and no attempt will be made to do so. The recent experiments of Field and Drinker (9) give information on this point. They state, "1. The capillaries under normal conditions are not concerned with the absorption of protein from the subcutaneous tissues. 2. After plasmapheresis, with substantial reduction of total blood protein, foreign protein placed in the subcutaneous tissues can be detected serologically in the blood when entrance by lymphatic routes has been blocked."

Speculation as to the comparative values of administering fluids intravenously and subcutaneously is not without interest. The intravenous 
route presents a disadvantage in some instances in which there is a marked decline in the blood pressure in that a marked decrease in the percentage of plasma protein results which is not due to an increase in the plasma volume and hence the osmotic pressure in the blood vessels is lowered. This disadvantage apparently does not exist when the decline in pressure results from hemorrhage. The main objection to the subcutaneous introduction of fluids is that the absorption is slow and especially so when the blood pressure is at a low level. This latter method is not as apt to result in a reduction of the percentage of protein in the serum. It would seem in the absence of a favorable response in the blood pressure following the intravenous introduction of a moderate amount of a solution such as normal salt solution that the injection should be discontinued before a marked decline in the concentration of protein is produced. Possibly the subcutaneous injection of fluids would be of some assistance in maintaining the level in pressure until arrangements for a blood transfusion could be made. Certainly the subcutaneous injection of fluids will tend to prevent the drop in pressure following procedures that are frequently associated with a slow decline.

\section{SUMMARY}

The effects on the composition of the blood of the subcutaneous introduction of normal salt solution into dogs have been determined repeatedly under the following experimental conditions: (1) control studies on the injection alone, (2) trauma to the intestines, (3) the graded removal of blood and (4) the subcutaneous injection of histamine. The studies included determinations of the arterial pressure, the percentage of hemoglobin, the concentration of the red blood cells, the blood volume, the percentages of total protein, albumin and globulin in the blood serum and the volume of salt solution absorbed by the circulation.

The following are some of the results that were obtained.

1. In normal animals in which salt solution was injected under the skin, there was a slight increase in the volume of plasma, practically no alteration in the concentration and an increase in the absolute amounts of the protein constituents.

2. Trauma to the intestines and the subcutaneous injection of histamine were associated with a decrease in the volume of plasma, no definite change in the concentration of total protein, albumin and globulin and a marked decrease in the absolute amounts of the protein constituents. A smaller amount of the salt solution was absorbed by the circulation in these experiments than in the other ones.

3. The graded removal of blood was associated with a decrease in the concentration of the red blood cells, a slight diminution in the percentages of total protein, albumin and globulin in the blood serum, and an increase in the absolute amounts of the protein constituents if the amount of protein that was removed is included. 


\section{BIBLIOGRAPHY}

1. Beard, J. W., and Blalock, Alfred, J. Clin. Invest., 1932, xi, 249. Intravenous Injections. A Study of the Composition of the Blood During Continuous Trauma to the Intestines When No Fluid is Injected and When Fluid is Injected Continuously.

2. Blalock, Alfred, Beard, J. W., and Thuss, Charles, J. Clin. Invest., 1932, xi, 267. Intravenous Injections. A Study of the Effects on the Composition of the Blood of the Injection of Various Fluids Into Dogs with Normal and with Low Blood Pressures.

3. Beard, J. W., Wilson, H., Weinstein, B. M., and Blalock, A., J. Clin. Invest., 1932, xi, 291. A Study of the Effects of Hemorrhage, Trauma, Histamine and Spinal Anesthesia on the Composition of the Blood When No Fluids are Injected and When Fluids Are Introduced Intravenously.

4. Cohen, B., and Smith, A. H., J. Biol. Chem., 1919, xxxix, 489. The Colorimetric Determination of Hemoglobin.

5. Rowntree, L. G., Brown, G. E., and Roth, G. M. The Volume of the Blood and Plasma in Health and Disease, Mayo Clinic Monographs, 1929, W. B. Saunders Company, Philadelphia.

6. Howe, P. E., J. Biol. Chem., 1921, xlix, 109. The Determination of the Proteins in Blood-A Micro Method.

7. Gunning, J. W., Ztschr. f. Anal. Chem., 1889, xxviii, 188 . Ueber eine Modification der Kjeldahl-Methode.

8. Blalock, Alfred, Arch. Surg., 1930, xx, 959. Experimental Shock. The Cause of the Low Blood Pressure Produced by Muscle Injury.

9. Field, M. E., and Drinker, C. K., Am. J. Physiol., 1931, xciii, 66. Conditions Governing the Removal of Protein Deposited in the Subcutaneous Tissues of the Dog. 